\title{
An Evaluation of Urban Land Use Regulations from View of Urban Surface Albedo
}

\author{
Takashi Kyakuno*1', Masahiro Sotoma ${ }^{2}$, Hiroshi Miyazaki ${ }^{3}$ and Masakazu Moriyama ${ }^{4}$ \\ ${ }^{1}$ Chief researcher, Museum of Nature and Human Activities, Hyogo, Japan \\ ${ }^{2}$ Researcher, National Research Institute for Earth Science and Disaster Prevention, \\ Earthquake Disaster Mitigation Research Center, Kawasaki Laboratory, Japan \\ ${ }^{3}$ Lecturer, Inst. of Nature and Environmental Science, University of Hyogo, Japan \\ ${ }^{4}$ Professor, Dept. of Architecture and Civil Eng., Faculty of Eng., Kobe University, Japan
}

\begin{abstract}
Urban surface albedo, which is one of the important factors of the urban heat island phenomenon, was used to evaluate urban land use regulations. Broadband albedo at the surface level of Sakai City, Japan, was calculated, and effects of land use regulations and actual land use were estimated using satellite remote sensing data, a land use regulation map and detailed digital information expressing actual land use. Land use regulations define land use, maximum building coverage ratios and maximum floor area ratios, which relate the heights of buildings to the areas of their sites. These factors have effects upon broadband albedo and each narrowband albedo corresponding to wavelengths observed by Landsat ETM + . Albedo values differed according to land use regulation zones. The combination of land use regulation and actual land use is also meaningful in grasping urban surface albedo. But this relationship may provide only slight insight into the urban heat island phenomenon.
\end{abstract}

Keywords: broadband albedo; urban land use regulation; land use; remote sensing; urban heat island

\section{Introduction}

Urban environmental issues have become critical recently since urban areas have become conspicuously different from non-urban areas. The population of urban areas is predicted to continue to grow for several decades. This may trigger specific global environmental problems including the formation of UHIs (Urban Heat Islands). Appropriate urban planning may resolve some issues of urban areas including UHI, which should be also taken into account in urban planning systems as well as other issues. In this study, we have tried evaluating urban planning systems from the viewpoint of UHI in order to improve urban planning over the next several decades.

The UHI phenomenon, which refers to the higher air temperature in urban areas than in suburban areas, is currently one of the serious problems of urban areas. It has been pointed out that UHI increases energy consumption in summer and is harmful to human health through effects such as hyperthermia. Its causes have been reported to include: 1) Decrease of reflectance of solar irradiance (albedo), 2) Increase of impervious surfaces (i.e., decrease of natural areas such as green space and water, and increases in artificial surfaces) so that sensible heat prevails over latent heat, 3) Emittance of heat by consumption of energy,

*Contact Author: Takashi Kyakuno, Chief researcher, Museum of Nature and Human Activies, Hyogo

Yayoigaoka 6 Sanda Hyogo, Japan. Zip 669-1546

Tel: +81-79-559-2001 Fax: +81-79-559-2025

e-mail:kyakuno@hitohaku.jp

(Received May 10, 2004 ; accepted June 22, 2005) and 4) Increases in the heat-storing capacities of buildings (this means absorbing solar energy in the daytime and releasing it in the nighttime, respectively).

Reflectance of solar irradiance (albedo) was chosen as an indicator in evaluating urban environment among many factors of UHI. This is because albedo plays an important role in UHI and may be controlled more easily than the other factors and because the ratio of green coverage, which relates to impervious urban surfaces, has already been discussed in a previous study (Sotoma et al., 2003). Researchers have dealt with albedo from various perspectives (Aida, 1982; Brest et al., 1987; Kyakuno et al., 2002; Izumi et al., 2000; Nakagawa et al., 1992; Nakagawa et al., 1995; Nakagawa et al., 1996; Small et al., 2000; Zhao et al., 2000). Many kinds of method for evaluating and observing albedo have been proposed. However, they

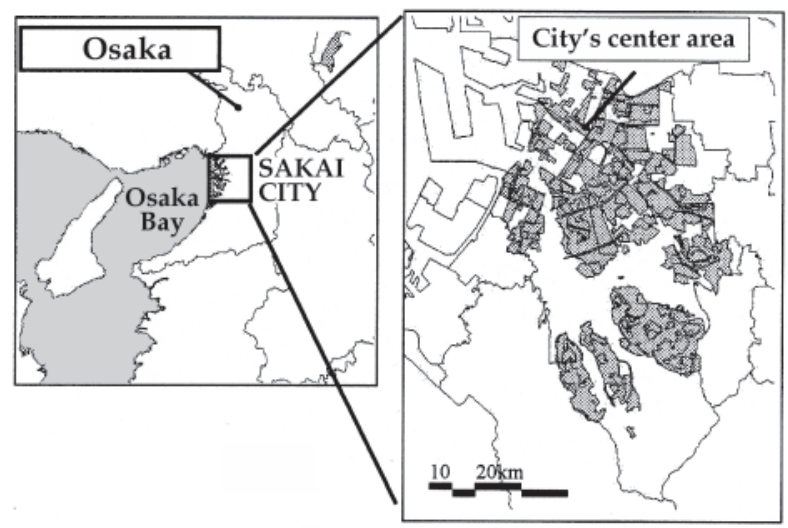

Fig.1. Study Area, Sakai City 
have never been discussed from the perspective of urban land use regulations, which are thought to be an effective and easy way to control land use in Japan.

This is a case study of Sakai city in Osaka prefecture (Fig.1.). Sakai city is about $10 \mathrm{~km}$ from downtown Osaka, the second largest city in Japan and a population center for the western area of Japan. The population of Sakai city is about 800,000 , and the area is about 136 $\mathrm{km}^{2}$. About 70 percent of the area is regulated by urban planning laws.

\section{Methods}

\subsection{Calculation of albedo}

In this study, short wave broadband surface albedo was calculated from narrowband planetary albedo through satellite remote sensing imagery. Broadband surface albedo means reflectance of solar irradiance at the earth's surface at wavelengths of $0.3 \mu \mathrm{m}-4.0 \mu \mathrm{m}$, while narrowband planetary albedo means reflectance at the top of the atmosphere in the limited bands of satellite observations. The reason why remote sensing data has been employed is that it makes possible the simultaneous measurement of albedo across a wide area. Imagery of Landsat ETM+ taken on the 25th of August 2000, which includes the Osaka area (path 110, row 36) was used because it contains few clouds and

Table 1. Assumed Reflectance of Sea Area in each Band

\begin{tabular}{c|c|c|c|c|c}
\hline $\begin{array}{c}\text { Band 1 } \\
0.45-0.52 \mu \mathrm{m}\end{array}$ & $\begin{array}{c}\text { Band 2 } \\
0.52-0.60 \mu \mathrm{m}\end{array}$ & $\begin{array}{c}\text { Band 3 } \\
0.63-0.69 \mu \mathrm{m}\end{array}$ & $\begin{array}{c}\text { Band 4 } \\
0.76-0.90 \mu \mathrm{m}\end{array}$ & $\begin{array}{c}\text { Band 5 } \\
1.55-1.75 \mu \mathrm{m}\end{array}$ & $\begin{array}{c}\text { Band 7 } \\
2.08-2.35 \mu \mathrm{m}\end{array}$ \\
\hline $1.50 \%$ & $1.70 \%$ & $0.70 \%$ & $0 \%$ & $0 \%$ & $0 \%$ \\
\hline
\end{tabular}

reveals the city in the summer, at which time UHI can be observed most conspicuously. The procedure of calculation was as follows:

1) Adopt the Eq.1 to transfer a digital number of Landsat data into each spectral radiance in Band 1 $(0.45-0.52 \mu \mathrm{m})$, Band $2(0.52-0.60 \mu \mathrm{m})$, Band 3 $(0.63-0.69 \mu \mathrm{m})$, Band $4(0.76-0.90 \mu \mathrm{m})$, Band 5 $(1.55-1.75 \mu \mathrm{m})$ and Band $7(2.08-2.35 \mu \mathrm{m})$, respectively (NASA, 2004).

$$
\begin{aligned}
R_{i}= & \frac{L M A X_{i}-L_{i}}{Q C A L M A X-Q C A L M I N}\left(D N_{i}-Q C A L M I N\right) \\
& + \text { LMIN }_{i}
\end{aligned}
$$

$R_{i}$ : Spectral Radiance at the sensor $i$ 's aperture in watts/(meter squared*ster* $\mu \mathrm{m}), L M A X_{i}$ : the spectral radiance that is scaled to $Q C A L M A X$ in watts/(meter squared*ster* $\mu \mathrm{m}), L_{M I N}$ : the spectral radiance that is scaled to $Q C A L M I N$ in watts/(meter squared*ster* $\mu \mathrm{m}), Q C A L M I N=1, Q C A L M A X=255, D N_{i}$ : the quantized calibrated pixel value in Digital Numbers, respectively. 2) Calculate means of solar irradiances in each wavelength band corresponding to an observation of Landsat with consideration given to the effects of a solar zenith angle and changes of the astronomic distance between the sun and the earth in Eq. 2 (NASA, 2004).

$$
S_{i}=\frac{D^{2} \pi R_{i}}{\cos \theta E S U N_{i}}
$$

$S_{i}$ : Spectral solar radiance at Band $i, D$ : Earth-Sun distance in astronomical units, $\theta$ : Solar zenith angle in degrees, $E S U N_{i}$ :

\begin{tabular}{|c|c|}
\hline Zones and their purposes (Symbol) & $\begin{array}{c}\text { Ratio to the site area } \\
\text { Maximum floor area ratios, \% (FAR) } \\
\text { Maximum building coverage area ratios, \% (BCR) }\end{array}$ \\
\hline Category I Exclusively Low-story Residential District (LR-I) & FAR: $50,60,80,100,150,200$ \\
\hline $\begin{array}{l}\text { Designated to ensure an excellent living environment for low-story } \\
\text { buildings. }\end{array}$ & BCR : $30,40,50,60$ \\
\hline Category II Exclusively Low-story Residential District (LR-II) & FAR: $50,60,80,100,150200$ \\
\hline $\begin{array}{l}\text { Designated to ensure an excellent living environment primarily for low- } \\
\text { story buildings. }\end{array}$ & BCR : $30,40,50,60$ \\
\hline Category I Exclusively Medium-high Residential District (MR-I) & FAR: $100,150,200,300,400,500$ \\
\hline $\begin{array}{l}\text { Designated to ensure an excellent living environment for } \\
\text { medium-high- rise buildings. }\end{array}$ & BCR : $30,40,50,60$ \\
\hline Category II Exclusively Medium-high Residential District (MR-II) & FAR: $100,150,200,300,400,500$ \\
\hline $\begin{array}{l}\text { Designated to ensure an excellent living environment primarily for } \\
\text { medium-high-rise buildings. }\end{array}$ & BCR : $30,40,50,60$ \\
\hline Category I Residential District (R-1) & FAR: $100,150,200,300,400,500$ \\
\hline Designated to ensure a living environment for buildings. & BCR : $50,60,80$ \\
\hline Category II Residential District (R-II) & FAR: $100,150,200,300,400,500$ \\
\hline Designated to ensure a living environment for buildings. & BCR : $50,60,80$ \\
\hline Quasi-residential District (QR) & FAR: $100,150,200,300,400,500$ \\
\hline $\begin{array}{l}\text { Designated primarily for promotion of businesses suited for the } \\
\text { characteristics of the neighborhood adjacent to roads, while at the } \\
\text { same time preserving an excellent living environment. }\end{array}$ & BCR : $50,60,80$ \\
\hline Neighborhood Commercial District (NC) & FAR: $100,150,200,300,400,500$ \\
\hline $\begin{array}{l}\text { Designated for promotion of convenience for conducting commercial } \\
\text { and other kinds of business to supply daily necessities to the } \\
\text { inhabitants in nearby residential areas. }\end{array}$ & BCR : 60,80 \\
\hline Commercial District (C) & $\begin{array}{l}\text { FAR : } 200,300,400,500,600,700,800,900, \\
1000,1100,1200,1300\end{array}$ \\
\hline $\begin{array}{l}\text { Designated primarily for promotion of convenience for commercial and } \\
\text { other kinds of business. }\end{array}$ & BCR : 80 \\
\hline Quasi-industrial District (QC) & FAR: $100,150,200,300,400,500$ \\
\hline $\begin{array}{l}\text { Designated primarily for promotion of convenience for industries which } \\
\text { are not likely to damage the environment. }\end{array}$ & BCR : $50,60,80$ \\
\hline Industrial District(l) & FAR: $100,150,200,300,400$ \\
\hline Designated primarily for promotion of convenience for industries. & BCR : 50,60 \\
\hline Exclusively Industrial District(EI) & FAR: $100,150,200,300,400$ \\
\hline Designated for promotion of convenience for industries. & BCR : $30,40,50,60$ \\
\hline Areas other than the Land-Use Zones & $\begin{array}{l}\text { FAR: } 50,80,100,200,300,400 \\
\text { BCR : } 30,40,50,60,70\end{array}$ \\
\hline
\end{tabular}
Mean solar exoatmospheric irradiances, respectively.

Table 2. Details of Land Use Zones Enacted by Building Standard Law (Sotoma et al., 2003; The Building Center of Japan, 1995.

Revised by the Authors.)

The numbers in the right column of each row refer to variations of permitted FAR and BCR in each zone. The Building Standard Law defines variations of FAR and BCR according to regulation zones. FAR of an area may be different to one of another area even if these belong to the same regulation zone. The same is true in the case of BCR. In general, buildings tend to be taller as FAR is higher. This is because permitted maximum areas of all floors become large. In the same way, building coverage areas against whole sites tend to become larger as BCR become higher. 


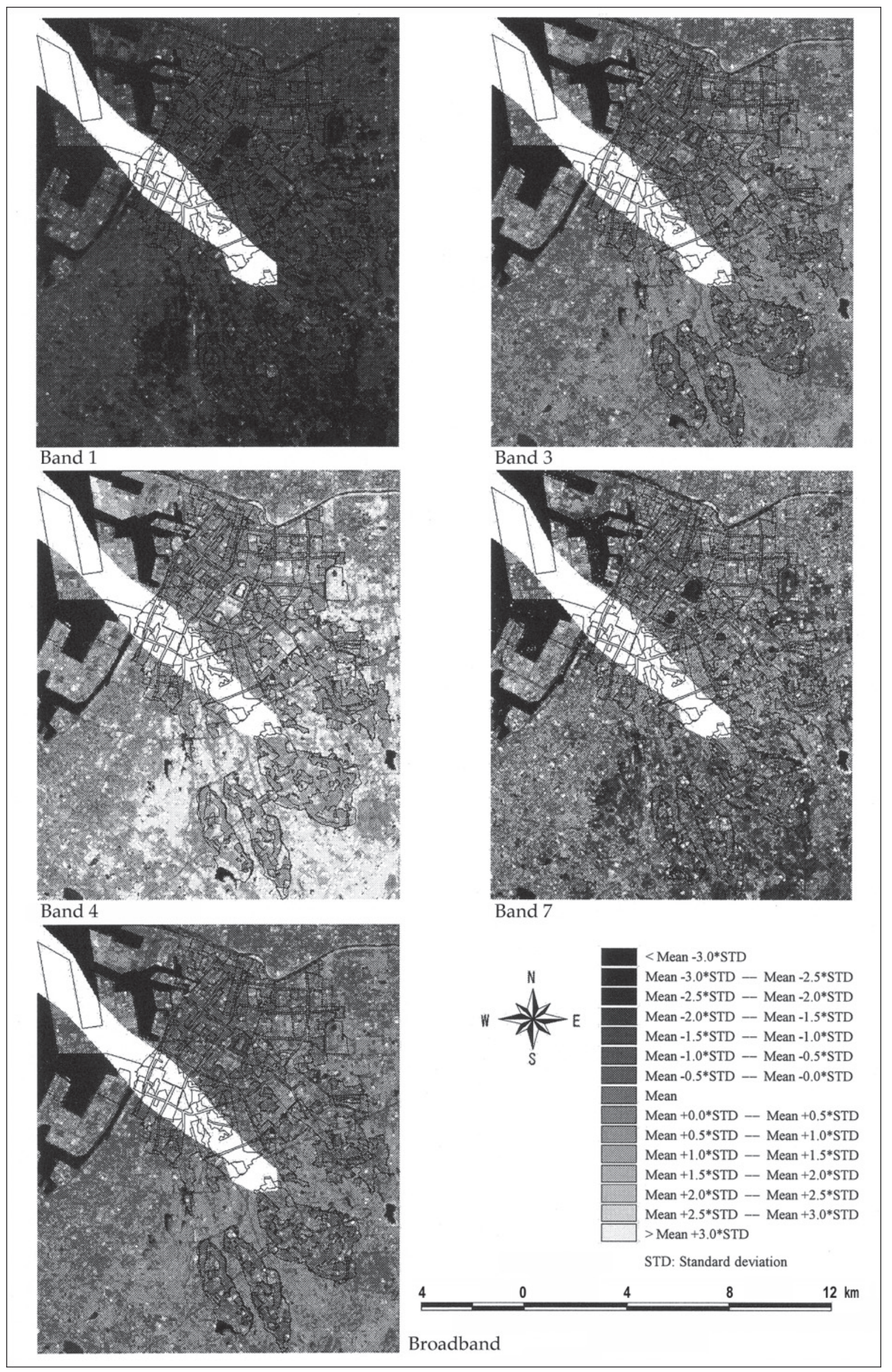

Fig.2. Spatial Distributions of Albedo in the Target Area. 
3) Implement atmospheric corrections by assuming reflectance of the sea area in each band as shown in Table 1., and estimate surface reflectance from planetary reflectance in each band.

4) Transfer the estimated reflectance of each band into broadband albedo by Eq. 3 (Liang et al., 2001).

$\alpha=0.356 \alpha_{1}+0.130 \alpha_{3}+0.373 \alpha_{4}+0.085 \alpha_{5}+0.072 \alpha_{7}$

$\alpha$ : Broadband surface albedo, $\alpha_{i}:$ surface reflectance at Band $i$ 's wavelength of Landsat ETM+, respectively.

The target area had a size of 591 pixels by 493 pixels and included Sakai city. Areas covered by clouds were excluded before the analysis. Each pixel had a resolution of $28.5 \mathrm{~m}$. The sample area before removal of cloudy areas was about $16.8 \mathrm{~km}$ by $14.1 \mathrm{~km}$. Fig.2. shows the spatial distributions of albedo in Band 1, Band 3, Band 4, Band 7 and Broadband in the target area. In the figure the depth of gray corresponds to classes defined with standard deviations and means of each band, and the white diagonal

Table 3. Numbers of Pixels of each BCR tabluated with LURZ

\begin{tabular}{|c|c|c|c|c|c|c|}
\hline & \multicolumn{4}{|c|}{$\begin{array}{c}\text { MAXIMUM BUILDING } \\
\text { COVERAGE RATIO }\end{array}$} & \multirow[t]{2}{*}{ Sum } \\
\hline & & 40 & 50 & .60 & 80 & \\
\hline \multirow{12}{*}{ 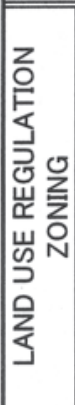 } & LR- I & 8094 & 3753 & - & - & 11847 \\
\hline & LR- II & - & - & 10607 & - & 10607 \\
\hline & MR-I & - & 122 & - & - & 122 \\
\hline & MR-II & $=$ & - & 26515 & - & 26515 \\
\hline & $R-I$ & - & $=$ & \begin{tabular}{|l|}
15099 \\
\end{tabular} & - & 15099 \\
\hline & R-II & - & - & 380 & - & 380 \\
\hline & $\overline{Q R}$ & - & - & 1885 & - & 1885 \\
\hline & $\mathrm{NC}$ & - & - & - & 6374 & 6374 \\
\hline & C & E & - & - & 3098 & 3098 \\
\hline & $\mathrm{QC}$ & E & - & 5198 & - & 5198 \\
\hline & - & $=$ & - & 2268 & - & 2268 \\
\hline & EI & - & - & 15553 & - & 15553 \\
\hline
\end{tabular}

Table 4. Numbers of Pixels of each FAR Tabluated with LURZ

\begin{tabular}{|c|c|c|c|c|c|c|c|c|c|c|}
\hline & \multicolumn{8}{|c|}{ MAXIMUM FLOOR AREA RATIO } & \multirow{2}{*}{ Sum } \\
\hline & & 80 & 100 & 200 & \begin{tabular}{|l|}
300 \\
\end{tabular} & 400 & 500 & 600 & 800 & \\
\hline \multirow{12}{*}{ 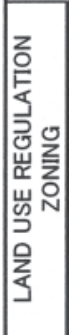 } & LR-I & 8094 & 3753 & - & $\overline{-1}$ & - & - & - & - & 11847 \\
\hline & LR-II & - & - & \begin{tabular}{|l}
10607 \\
\end{tabular} & - & - & - & - & - & 10607 \\
\hline & MR-I & - & 122 & - & - & - & - & - & - & 122 \\
\hline & MR-II & - & - & 26515 & - & - & - & - & - & 26515 \\
\hline & R-I & - & - & 15099 & - & - & - & - & - & 15099 \\
\hline & $R-$ II & - & - & 380 & - & - & - & - & - & 380 \\
\hline & QR & - & - & \begin{tabular}{|l}
1885 \\
\end{tabular} & - & - & - & - & - & \begin{tabular}{|c|c|}
1885 \\
\end{tabular} \\
\hline & NC & - & - & \begin{tabular}{|l|l|}
324 \\
\end{tabular} & 6050 & - & - & - & - & 6374 \\
\hline & C & - & - & 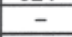 & - & 1975 & 31 & 1028 & 64 & 3098 \\
\hline & $Q C$ & - & - & \begin{tabular}{|l|}
5198 \\
\end{tabular} & - & - & - & - & - & 5198 \\
\hline & 1 & $=$ & - & \begin{tabular}{|l|}
2268 \\
\end{tabular} & - & - & - & - & - & \begin{tabular}{|l|}
2268 \\
\end{tabular} \\
\hline & EI & - & - & 15553 & - & - & - & - & - & 15553 \\
\hline
\end{tabular}

Table 5. Land Use Classes Adopted from Detailed Digital Information

\begin{tabular}{c|c}
\hline Class & Symbol \\
\hline Low-Story Residential area & LSRe \\
\hline Midium-High-Story Residential area & HSRe \\
\hline High-Density-Low-Story Residential area & HDLSRe \\
\hline Commercial or Business area & CoBu \\
\hline Industrial area & Ind \\
\hline Street or Road & StRo \\
\hline River, Lake or Pond & RiLaPo \\
\hline Sea & Sea \\
\hline Mountainous area & Mount \\
\hline Park or Greenery area & PaGr \\
\hline Paddy Field & PaFi \\
\hline Other Vegitable Field & OVeFi \\
\hline
\end{tabular}

striped areas are cloudy areas. Overlaid are outlines of regulatory zones from urban land use regulations.

\subsection{Land Use Regulations}

Japanese land use regulations are usually precisely governed by the Building Standard Law and Urban Planning Law. They consist of three main factors. The first is 'Land Use Regulation Zoning (LURZ)' (Table 2.), which usually has 12 classes except for special regulations and controls the kinds of architecture to be built. The second is 'Maximum Building Coverage Ratio (BCR)' which means the ratio of the area upon which buildings are permitted relative to the total site area. The third is 'Maximum Floor Area Ratio (FAR)' which is the ratio of the areas of all floors to that of the site. Although there are also many other precise descriptions including building height, setback distances, and building form, we used these three as land use regulation factors because they are the most significant and basic for determining actual urban land use in Japan.

Fig.3., Table 3. and Table 4. show the distribution of land use regulation zones in Sakai, pixel numbers of each BCR tabulated with each LURZ and pixel numbers of each FAR tabulated with each LURZ without cloudcovered areas, respectively. Pixel sizes have been resized into $28.5 \mathrm{~m}$ by $28.5 \mathrm{~m}$, which corresponds to the pixel size of the Landsat ETM+ data.

\subsection{Overlaying land use maps and averaging albedo in each land use category}

Detailed digital information from 1996 was employed as ground truth data of the target area in order to ascertain actual land use (GSI, 2001). It defines the spatial distribution of land use at a resolution of $10 \mathrm{~m}$, using 17 land use categories. Of them, 12 categories were chosen as ground truth data for this study (Table 5.). The land use regulation map used in this study was issued as GIS data by the Sakai city government.

Albedo distribution maps calculated through the above-mentioned procedure and the two abovementioned maps were overlaid in GIS in an affine

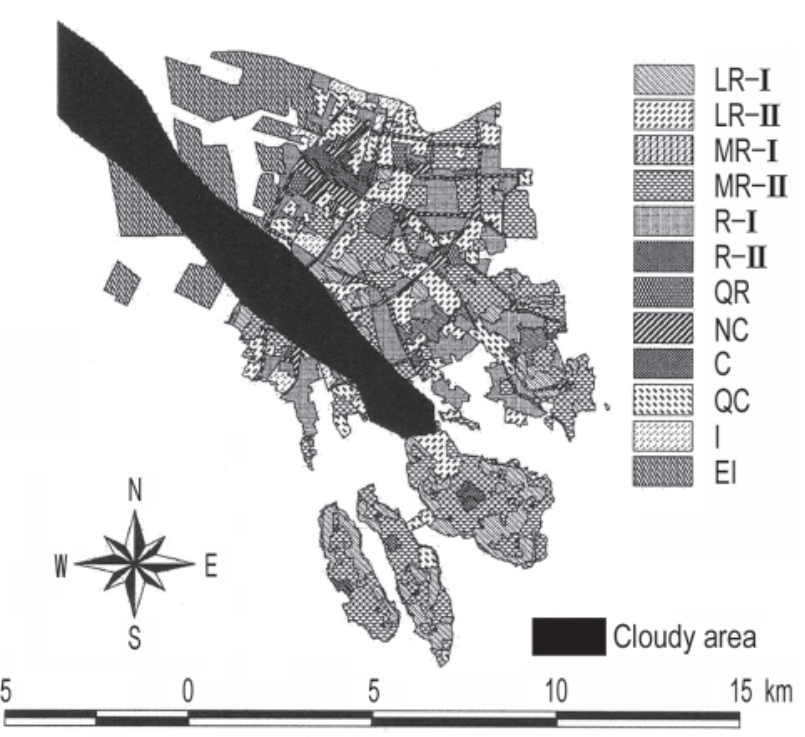

Fig.3. Distribution of LURZ in the Target Area. 
transformation, and relations between albedo and land use regulations from the viewpoints of actual land use were analyzed.

\section{Results and discussion}

\subsection{Albedo from the perspective of land use regulations}

Albedo in each band categorized with LURZ was averaged (Fig.4. and Table 6.), and T-tests were employed to testify the differences between each pair of categories in all bands (Table 7.). Values of Commercial Districts (C), Neighborhood Commercial District (NC) and Category I Low-Story Residential District (LR-I) are lower by about $1 \%$ than the other categories in the broadband albedo. On the other hand, Quasi Residential District (QR), Quasi Commercial District (QC), and Category II Middle-Story Residential District (MR-II), in which more kinds of land use are permitted than in the other zones, have higher albedos. Values for each visiblelight band (Bands 1-3) were similar while values of near infrared or infrared wavelength bands (Bands 4, 5 and 7) differed from each other. The T-test illustrates that the differences of most pairs of $L U R Z$ are statistically significant except for cases relating to Category $I$ Middle-story Residential District (MR-I). This means that $M R-I$ has average spectral characteristics among all zonings and ordinal status in urban areas.

In the same way, values of albedo for each BCR or each FAR were calculated (Fig.5., Fig.6., Table 8. and Table 10.), and T-tests were executed (Table 9. and Table 11). The albedo value for BCR $60 \%$ tended to be the highest except in the case of visible bands (Bands 1-3). Broadband albedo was highest at BCR $60 \%$. As to FAR, broadband albedo was higher in $200 \%, 500 \%$ and $600 \%$ FAR than in the others. This is mainly because the values of Bands 4 and 7 are higher for these FAR values. Visible-band albedo (Bands 1-3) becomes higher as BCR or FAR increase. T-test results show most pairs in BCR having a significant difference, which means that BCR influences the albedo of each band. The same is true of FAR, in which case FAR can be regarded to affect the albedo of each band as well.

It can be concluded that both LURZ, BCR and FAR have effects on the albedo of each band since differences of most pairs of LURZ, BCR and FAR are statistically significant. However, the differences are slight in most cases: no more than $2.0 \%$ in broadband albedo. The T-test results show that land use regulations generate different values of albedo in different regions, but do not certify that the differences are meaningful from the perspective of the Urban Heat Island phenomenon. These kinds of regulation alone are not sufficient to control the albedo for the purpose of mitigating the UHI phenomenon, though they make a slight difference.

\subsection{Albedo from the perspective of actual land use} and land use regulations

In this section the effects of actual land use and combinations of land use regulations and actual land

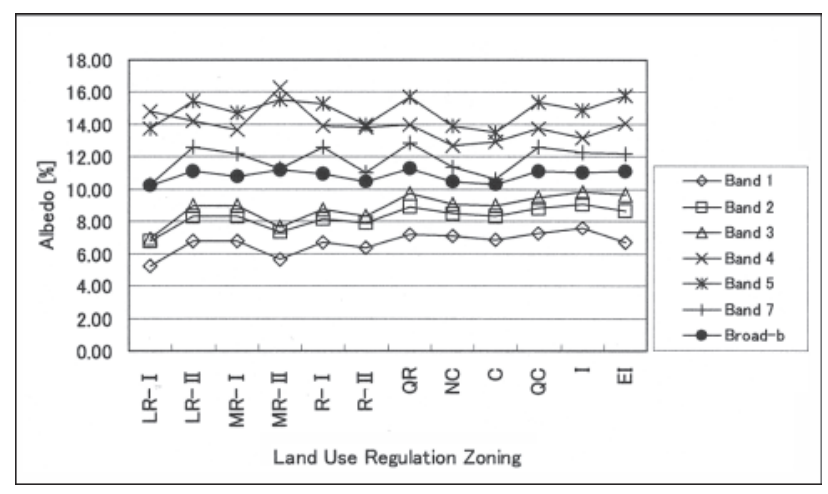

Fig.4. Means of Albedo in each Land Use Regulation Zoning

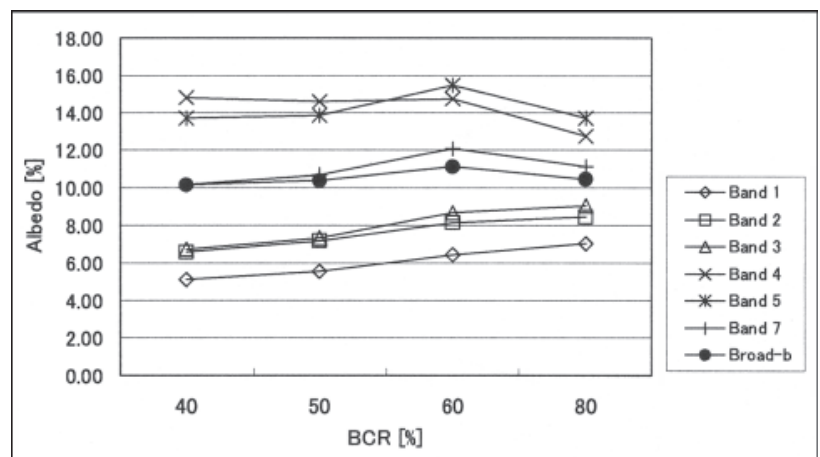

Fig.5. Means of Albedo in each Building Coverage Ratio

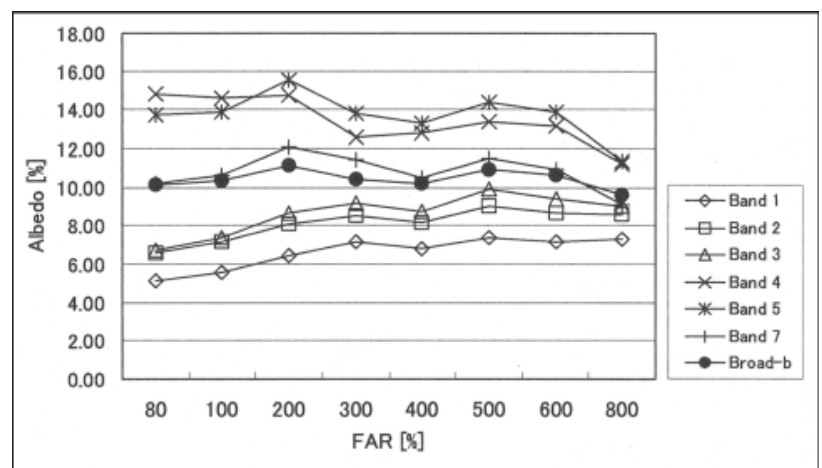

Fig.6. Means of Albedo in each Floor Area Ratio

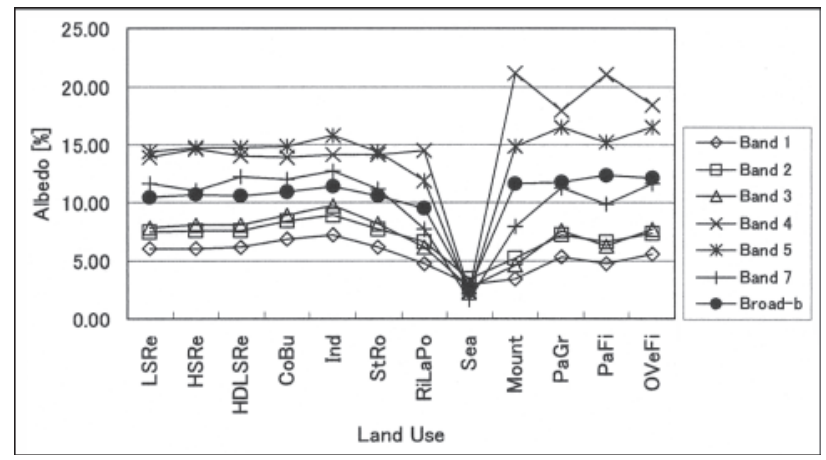

Fig.7. Means of Albedo in each Land Use Class

use are discussed. As mentioned before, land use regulations including $\mathrm{BCR}$ and FAR define actual land use roughly but not precisely. For instance, in the Commercial District category, most uses are permitted including homes and small-scale industry, as well as commercial buildings. These areas have a variety of structures and building styles. The same is true in the case of FAR: a large FAR means that various types of buildings may be built in the area. 
Table 6. Means of Albedo in each Land Use Regulation Zoning

Band $1 \mid$ Band $2 \mid$ Band $3 \mid$ Band $4 \mid$ Band $5 \mid$ Band $7 \mid$ Broad-b \begin{tabular}{|l|l|l|l|l|l|l|l|}
\hline & & & & & \\
\hline LR-I & 5.26 & 6.76 & 6.92 & 14.78 & 13.74 & 10.29 & 10.19 \\
\hline
\end{tabular} \begin{tabular}{|l|l|l|l|l|l|l|l|}
\hline LR- II & 6.83 & 8.38 & 9.00 & 14.22 & 15.44 & 12.63 & 11.13 \\
\hline
\end{tabular} \begin{tabular}{|l|l|l|l|l|l|l|l|}
\hline MR-I & 6.79 & 8.32 & 8.98 & 13.64 & 14.70 & 12.20 & 10.80 \\
\hline
\end{tabular}

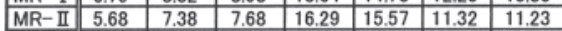

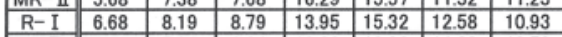
\begin{tabular}{|c|c|c|c|c|c|c|c|}
\hline$R-I$ & 6.68 & 8.19 & 8.79 & 13.95 & 15.32 & 12.58 & 10.93 \\
\hline$R-I I$ & 6.42 & 7.91 & 8.34 & 13.80 & 13.98 & 11.03 & 10.50 \\
\hline
\end{tabular} \begin{tabular}{|l|l|l|l|l|l|l|l|}
\hline$R-$ II & 6.42 & 7.91 & 8.34 & 13.80 & 13.98 & 11.03 & 10.50 \\
\hline OR & 7.22 & 8.91 & 9.70 & 14.03 & 15.68 & 12.82 & 11.32 \\
\hline
\end{tabular} \begin{tabular}{|l|l|l|l|l|l|l|l|}
\hline QR & 7.22 & 8.91 & 9.70 & 14.03 & 15.68 & 12.82 & 11.32 \\
\hline NC & 7.10 & 8.50 & 9.09 & 12.72 & 13.87 & 11.37 & 10.45 \\
\hline
\end{tabular} \begin{tabular}{|l|l|l|l|l|l|l|l|l|}
\hline NC & 7.10 & 8.50 & 9.09 & 12.72 & 13.87 & 11.37 & 10.45 \\
\hline \hline
\end{tabular} \begin{tabular}{|l|l|l|l|l|l|l|l|}
\hline $\mathrm{C}$ & 6.91 & 8.38 & 8.98 & 12.89 & 13.47 & 10.60 & 10.34 \\
\hline $\mathrm{QC}$ & 7.27 & 8.82 & 9.50 & 13.75 & 15.35 & 12.58 & 11.16 \\
\hline
\end{tabular} \begin{tabular}{|c|c|c|c|c|c|c|c|}
\hline QC & 7.27 & 8.82 & 9.50 & 13.75 & 15.35 & 12.58 & 11.16 \\
\hline I & 7.57 & 9.08 & 9.81 & 13.15 & 14.89 & 12.26 & 11.02 \\
\hline
\end{tabular} \begin{tabular}{|c||c|c|c|c|c|c|c|}
\hline I & 7.57 & 9.08 & 9.81 & 13.15 & 14.89 & 12.26 & 11.02 \\
\hline EI & 6.71 & 8.68 & 9.62 & 14.05 & 15.82 & 12.17 & 11.10 \\
\hline
\end{tabular}

Table 8. Means of Albedo in each Building Coverage Ratio

\begin{tabular}{|l||r|r|r|r|r|r|r|}
\hline & Band 1 & Band 2 & Band 3 & Band 4 & Band 5 & Band 7 & Broad-b \\
\hline \hline 40 & 5.12 & 6.58 & 6.73 & 14.85 & 13.71 & 10.16 & 10.13 \\
\hline 50 & 5.59 & 7.16 & 7.37 & 14.60 & 13.85 & 10.64 & 10.34 \\
\hline 60 & 6.44 & 8.12 & 8.70 & 14.77 & 15.51 & 12.06 & 11.12 \\
\hline 80 & 7.03 & 8.46 & 9.06 & 12.77 & 13.74 & 11.11 & 10.41 \\
\hline
\end{tabular}

Table 10. Means of Albedo in each Floor Area Ratio

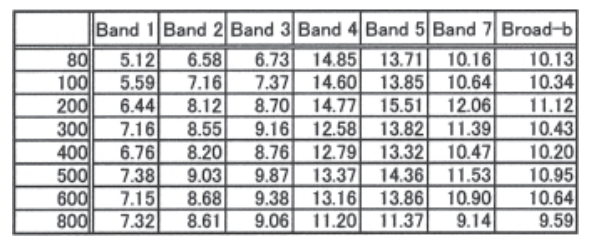

Table 12. Means of Albedo in each Land Use Class

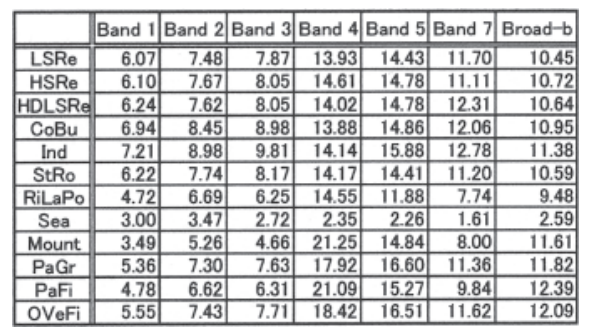

Table 7. T-tests for Differences between each Pair of LURZ

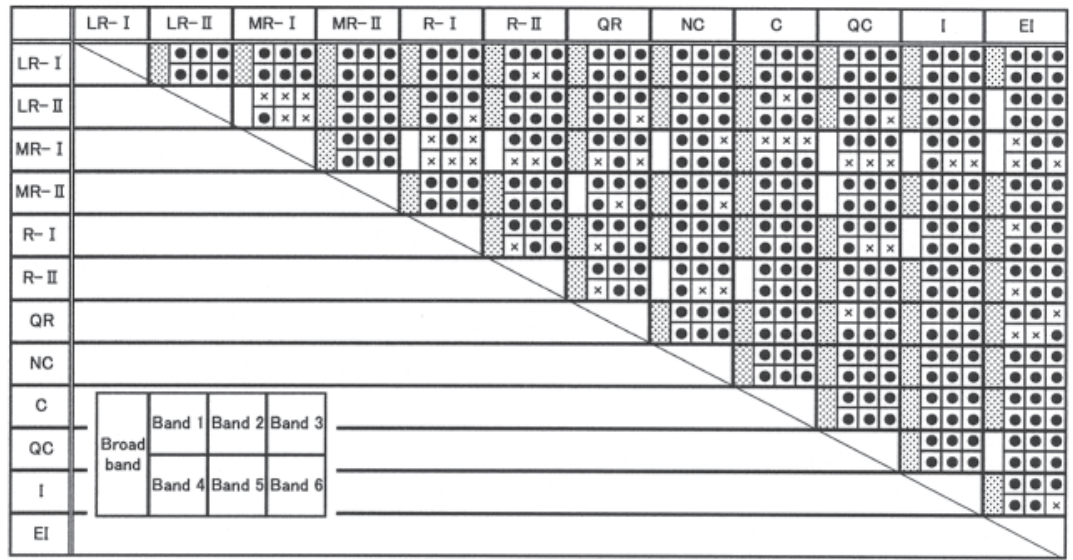

Hatched rectangle refers to "significant at $\alpha=0.05$ in broadband albedo". Checking with dot refers to "significant at $\alpha=0.05$ in considered band".

Table 9. T-tests for Differences between each Pair of BCR

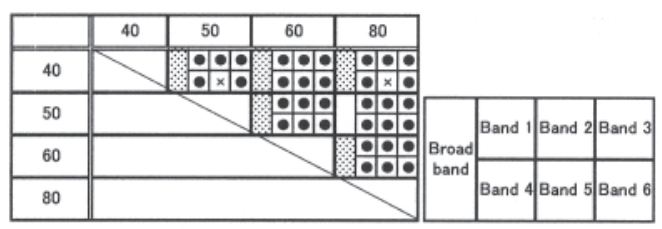

Hatched rectangle refers to "significant at $\alpha=0.05$ in broadband albedo". Checking with dot refers to "significant at $\alpha=0.05$ in considered band".

Table 11. T-tests for Differences between each Pair of FAR

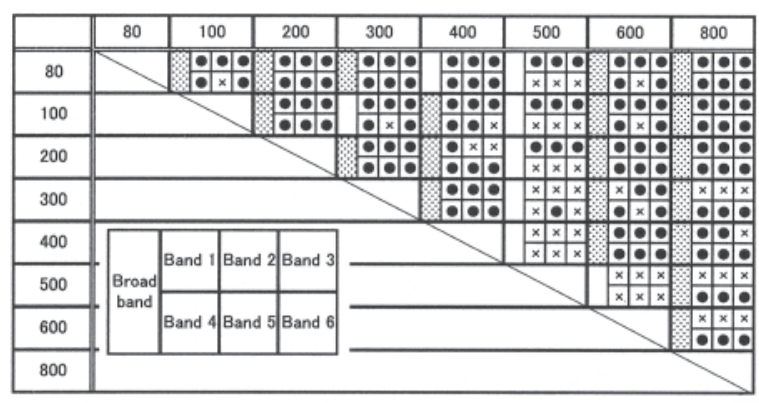

Hatched rectangles refers to "significant at $\alpha=0.05$ in broadband albedo". Checking with dots refers to "significant at $\alpha=0.05$ in considered band".

Table 13. T-tests for Differences between each Pair of Land Use Class

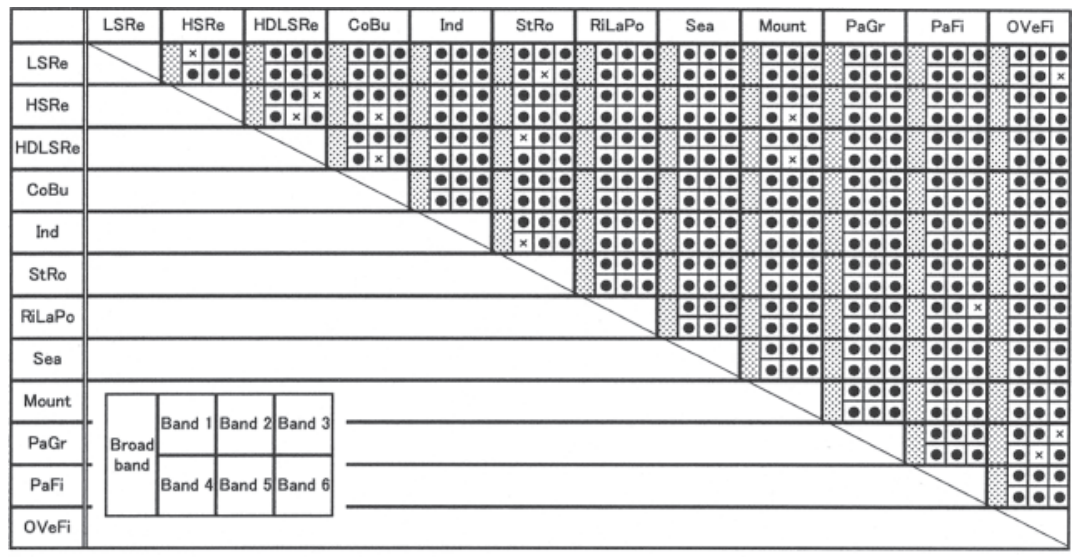

Hatched rectangle refers to "significant at $\alpha=0.05$ in broadband albedo". Checking with dot refers to "significant at $\alpha=0.05$ in considered band". 
Table 14. Average Broadband Albedo and Standard Deviations of each Categorized Combination Made of Land Use Regulation Zoning and Actual Land Use

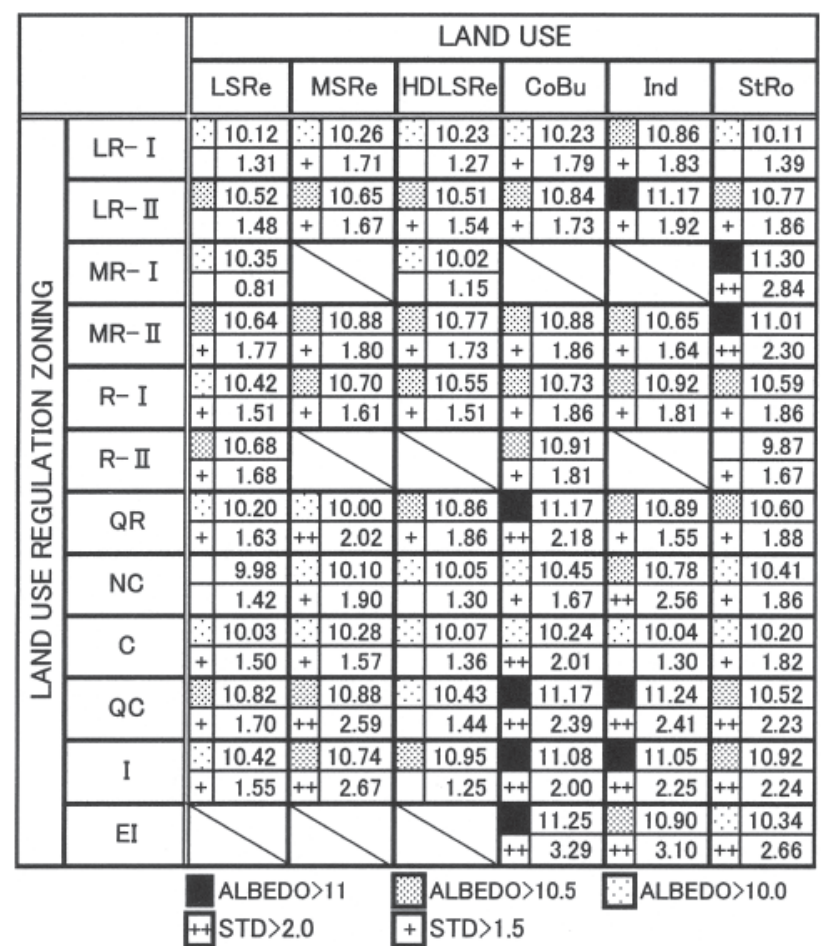

Upper cell: Average albedo Lower cell: Standard deviation

Table 15. Average Broadband Albedo and Standard Deviations of each Categorized Combination Made of Maximum Building Coverage Ratio and Actual Use

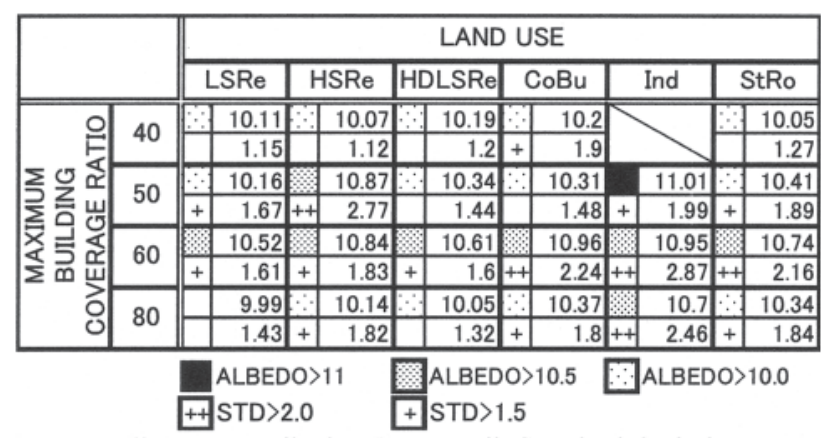

Upper cell: Average albedo Lower cell: Standard deviation

Table 16. Average Broadband Albedo and Standard Diviations of each Categorized Combination Made of Maximum Floor Area Ratio and Actual Land Use

\begin{tabular}{|c|c|c|c|c|c|c|c|c|}
\hline & \multicolumn{7}{|c|}{ LAND USE } \\
\hline & & LSRe & HSRe & HDLSRe & $\mathrm{CoBu}$ & Ind & & StRo \\
\hline \multirow{13}{*}{ 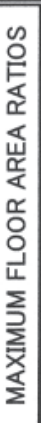 } & \multirow{2}{*}{80} & 10.11 : & 10.07 & 10.19 & 10.2 & & & 10.05 \\
\hline & & 1.15 & 1.12 & 1.2 & 1.9 & 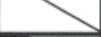 & & 1.27 \\
\hline & \multirow{2}{*}{100} & 10.16 & 10.87 & 10.34 & 10.31 & 11.01 & 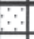 & 10.41 \\
\hline & & 1.67 & 2.77 & 1.44 & 1.48 & 1.99 & + & 1.89 \\
\hline & \multirow{2}{*}{200} & 10.52 & 10.84 & 10.61 & 10.96 & 10.95 & \% & 10.74 \\
\hline & & 1.61 & 1.82 & 1.6 & 2.24 & 2.87 & ++ & 2.15 \\
\hline & \multirow{2}{*}{300} & 9.97 & 10.03 & 10.03 & 10.41 & 10.78 & $\because$ & 10.4 \\
\hline & & 1.42 & 1.97 & 1.3 & 1.65 & 2.56 & + & 1.86 \\
\hline & \multirow{2}{*}{400} & 9.92 & 10.23 & 9.93 & 9.92 & 9.97 & $\because$ & 10.1 \\
\hline & & 1.37 & 1.57 & 1.33 & 1.56 & 1.16 & + & 1.8 \\
\hline & \multirow[t]{2}{*}{600} & & & & $\frac{10.89}{2.57}$ & 10.1 & $\because$ & 10.34 \\
\hline & & & & & 2.57 & 1.42 & + & $\frac{1.85}{9.82}$ \\
\hline & 800 & & & & 0.9 & & & 1.02 \\
\hline
\end{tabular}

Upper cell: Average albedo Lower cell: Standard deviation
The average albedo in each band categorized by land use was calculated (Fig.7., Table 12.), and T-tests were implemented to test differences in average albedo of each land use (Table 13.). There were conspicuous differences between these classes, especially for Bands 4, 5 or and 7. Housing areas such as Low-Story Residential area (LSRe), Medium-HighStory Residential area (HSre), High-Density-LowStory Residential area (HDLSRe), and Commercial or Business area (COBU) had lower values by 2-3 percent in the broadband albedo than Paddy Field (PaFi) or Mountainous area (Mount). The lowest value was the Sea area, and the highest was in the Paddy Field. River, Lake or Pond (RiLaPo) had much higher values than the Sea area, probably because these areas in the database contain extensive bare ground such as baseball fields. Values of Bands 1-3 showed similar tendencies in all land use classes. On the contrary, the values of Band 4, Band 5 and Band 7 showed distinct differences according to land use; for instance, the values of Band 4 in Mountainous area and Paddy Field were much higher than in the other land use areas. The T-tests also certified that values of albedo differ significantly according to land use.

Albedo values were also investigated from the point of view of a combination of Land Use Regulation Zoning (LURZ) and actual land use. Of all land use classes, those relating to LURZ including residential areas, commercial areas and industrial areas were extracted in advance. Average broadband albedo and standard deviations were calculated in categorized combinations made of each LURZ and each land use class (Table 14.). The combination of $M R-I$ and StRo had the highest value among all categories, and the second highest was shown in the combination of Exclusively Industrial District (EI) and Commercial or Business area $(\mathrm{CoBu})$. The lowest value was observed in the combination of MR-II and Street or Road (StRo). Generally, combinations relating to $C o B u$ had high values of albedo, and ones relating to LSRe had relatively low values. However, these differences are no more than 2 percent.

Standard deviations show variability of albedo associated with $C o B u$ and Industrial area (Ind), which have high standard deviations in all LURZ. This means that land use such as Ind and $C o B u$ have diverse albedo values because these areas typically consist of a variety of land coverage including concrete buildings, asphalt grounds and greenery.

Combinations made of BCR and actual land use, and combinations of FAR and actual land use were examined in the same way (Tables 15 and 16). There are some significant differences of values depending on the combinations. As to BCR, the highest value was shown in the combination of $50 \% \mathrm{BCR}$ and Ind while the lowest value was observed in the combination of $80 \% \mathrm{BCR}$ and LSRe. Categories relating to $60 \% \mathrm{BCR}$ tended to have high values in both albedo and standard deviations 
in every land use class. Table 3 . indicates that the $60 \%$ BCR class includes many kinds of LURZ, which generates diversities among these combinations. In case of FAR, the combination of $100 \%$ FAR and Ind had the highest value while the lowest value was observed in the combination made of $800 \%$ FAR and CoBu. In most cases combinations relating to $200 \%$ FAR showed high values. $60 \% \mathrm{BCR}$ and $200 \%$ FAR areas combined with Commercial or Business area, or Industrial area showed higher values than the others. However, these differences were slight, no more than 2 percent.

It would be difficult to conclude that albedo can be controlled through regulating LURZ, BCR or FAR. Japanese land use regulations do not refer to precise land uses or land coverage. Each category allows various land uses or land coverage. The same is true for BCR or FAR, which provide only upper limits; ratios below these limitations are allowed.

\section{Conclusion}

Broadband albedo and narrowband albedo in wavelengths corresponding to observation of Landsat ETM+ were discussed from the perspective of urban land use regulations and actual land use. Albedo was shown to be influenced by both land use regulations and actual land uses, and combinations of these categories were also meaningful for considering albedo. For instance, Commercial or Business area had high albedos, but these albedos differed according to LURZ. BCR and FAR showed peak albedos around $80 \%$ BCR and $200 \%$ FAR, respectively.

Land use regulations, actual land use and the combinations of these factors are not the dominant factors defining albedo, however. The differences generated by these factors are statistically significant, but are no more than 2 percent: not enough to consider controlling albedo through land use regulations. Land coverage may also play an important role for albedo. Even if a place is labeled as "Industrial area" in a land use category, it may include roof-covered areas, asphalt areas, greenery and bare soil, all of which have different spectral reflectance characteristics. What is needed is a regulating system that refers to land coverage as well as current land use regulations for easing the heat island phenomenon through controlling albedo.

In our further studies, the effects of land coverage upon albedo and its management through land use regulation will be discussed by focusing on the relation between land use regulations, actual land use and actual land coverage.

\section{Acknowledgment}

We are grateful to the Sakai City Government for offering urban land use regulation data, and to RESTEC for providing Landsat ETM+ data that had been received by JAXA.

\section{References}

1) Aida, M. (1982) Urban albedo as a function of the urban structure a model experiment. Boundary-Layer Meteorology, 23, pp.405-413

2) Brest, C. L. et al. (1987) Deriving surface albedo measurements from narrow band satellite data. INT. J. REMOTE SENSING, 8(3), pp.351-367

3) Geographical Survey Institute (1999) Detailed Digital InformationKinki area, 1996

4) Izumi, T. et al. (2000) The effect of the shadow of buildings on the satellite derived albedo in urban area using 3-dimensional building data and remotely-sensed data. Theory and Applications of GIS, 8, pp.11-18 (written in Japanese)

5) Kyakuno, T. et al. (2002) Study on utilization of remote sensing data to urban planning focusing on Thermal environment - Study on estimation of Albedo and its relation to land-coverage and landuse -. Journal of Archit. Plann. Environ. Engng., 562, pp.69-74 (written in Japanese)

6) Liang, S. et al. (2002) Atmospheric correction of Landsat ETM+ land surface imagery :II. Validation and applications. IEEE TRANSACTIONS ON GEOSCIENCE AND REMOTE SENSING, vol. 40, No.12, pp.2376-2746

7) Nakagawa, K. et al. (1992) The surface albedo distribution and its seasonal change over the Nagaoka area, Niigata prefecture, central Japan, estimated with LANDSAT/MSS DATA. Geographical Review of Japan, 65A-10, pp.769-790 (written in Japanese)

8) Nakagawa, K. et al. (1995) The relationship between surface albedo and surface structure in the central parts of urban areas in the Kanto plain, Japan. Geographical Review of Japan, 68A-11, pp.741-760 (written in Japanese)

9) Nakagawa, K. (1996) The dependence of surface albedo on the sky view factor in the built-up area of Takada, Niigata, Japan. Geographical Review of Japan, 68A-9, pp.603-620 (written in Japanese)

10) NASA (2004.4) Landsat 7 Science Data Users Handbook, http://ltpwww.gsfc.nasa.gov/IAS/handbook/handbook_htmls/ chapter11/chapter11.html

11) Sotoma, M. et al. (2003) Analysis of land use zoning regulation and Green Coverage Ratio. Journal of Asian Architecture and Building Engineering, vol. 2 no. 2, pp.29-34

12) Small, C. (2000) Multitemporal analysis of urban reflectance. Remote Sensing of Environment, 81, pp.427-442

13) The Building Center of Japan (1995) Introduction to the Building Standard Law

14) Zhao, W. et al. (2000) Atmospheric and spectral corrections for estimating surface albedo from satellite data using $6 \mathrm{~S}$ code. Remote Sensing of Environment, 76, pp.202-212 